\title{
Self-Ear Cleaning Practices and the Associated Risks: A Systematic Review
}

\author{
Linda N Lukolo ${ }^{1}$, Lukanga C Kimera ${ }^{2} \&$ Gentz Pilbee ${ }^{3}$ \\ ${ }^{1}$ Department of Community \& Family Medicine, Faculty oh Health Sciences, University of Namibia, Namibia \\ ${ }^{2}$ Department of Obstetrics \& Gynaecology, Faculty of Health Sciences, University of Namibia, Namibia \\ ${ }^{3}$ School of Medicine, Faculty of Health Sciences, University of Namibia, Namibia \\ Correspondence: Linda N Lukolo, Department of Community \& Family Medicine, Faculty oh Health Sciences, \\ University of Namibia, Namibia.
}

Received: October 22, 2020 Accepted: March 1, 2021 Online Published: March 30, 2021

doi:10.5539/gjhs.v13n5p44 URL: https://doi.org/10.5539/gjhs.v13n5p44

\begin{abstract}
Background: Naturally the ear produces soft wax from the sebaceous and ceruminous gland. This is what is referred to as earwax. This wax is important for protection of the ear by trapping dust and other foreign particles that could damage the eardrum. It also has some antibacterial properties. Jaw movements, like during chewing, moves the old earwax from inside the ear canal to the outside and finally flakes off. Build-up of this wax in the ear causes hearing loss, pain in the ear, irritation, dizziness and ringing in the ears. Self-ear cleaning refers to self-insertion of objects into the ear canal, with an attempt to remove the wax to get rid of these symptoms. It is a common practice amongst many individuals. Potentially, this rids the ear of its protective defences in addition to posing a risk of ear related injuries. This review paper aims to determine the prevalence of self-ear cleaning, the common methods used and the complications associated with this practice.

Methods: Electronic retrieval of articles for review was done from PubMed, Google and Google scholar with key-ward - self-ear cleaning, ear-wax, cerumen. Many articles were retrieved but only a few were about self-ear cleaning and only seven could be included in this review. The inclusion criteria included: article published in English language; study carried between 2005 and 2020 inclusive; article discussing materials used and complications associated with self-ear cleaning. Articles older than 15 years or published in languages other than English were excluded.
\end{abstract}

Results: On average the prevalence of self-ear cleaning amongst all studies was $76.6 \%$. The commonest method used for ear cleaning was cotton buds with an average of $69.6 \%$. Wax/dirt removal was the commonest reason for engaging in this practice. Several complications arising from this practice included perforation of eardrum, retained foreign body and otitis externa.

Conclusion: In addition to ridding the ear of its natural protection, self-ear cleaning is associated with a risk of injury to the ear drum and retention of foreign bodies. Community education to avoid this practice is therefore of paramount importance. Trained health care providers should be consulted whenever someone has a problem related to hearing or any other symptoms.

Keywords: cerumen, cotton bud use, ear-injury, earwax, self-ear cleaning

\section{Introduction}

Self-ear cleaning is the practice of inserting an object into the ear canal with the aim of cleaning the internal part of the ear. However, this practice potentially compromises the integrity of the natural cleansing mechanism of the ear, and pose a risk to possible injuries (Khan, Thaver, \& Govender, 2017). It is not uncommon for people to get rid of wax in their ears and it is a global assumption that wax is considered dirt, despite its physiological usefulness of protecting the ear from dust and foreign bodies. The ear has a physiological, natural cleansing mechanism, thus the practice of inserting objects into the ear canal for cleaning it is not necessary and may be harmful. There are risks of inflicting injury to the ear and in worse cases these complications may need urgent medical attention i.e., tympanoplasty or instrumental removal of retained objects. These complications may lead to life-long sequelae, such as hearing impairment (Khan, Thaver, \& Govender, 2004). Common objects inserted into the ear canal include cotton buds, matchstick, broomsticks, tree twigs, towel tips, ball pen tips or their covers and the fingers. Inserting these objects into the ear may disturb its normal $\mathrm{pH}$, function and anatomical structure (perforation). 
There is lack of understanding the importance of consulting a trained health professional in the case of ear problems such as itch, dizziness, loss of hearing due to wax impaction, etc. Health professionals are trained to clean ears by safer means if medically required.

Ear wax lubricates, cleans and protects the external auditory canal. Self-ear cleaning rids the ear of this wax and potentially leads to ear infections, trauma and perforation of the tympanic membrane as objects are inserted blindly into the ear canal. Wax removal alters the integrity of the ear's natural physiological defences. Ignorance of this fact leads to wrong practices with serious consequences (Oladeji, Babatunde, Babatunde, \& Sogebi, 2015). Several hospital-based studies have shown that self-ear cleaning is common in several countries including Nigeria, Malaysia, England, and the United States. A study on "Self-Ear-Cleaning Among Educated Young Adults in Nigeria by Olaosun (2014) showed that $90 \%$ of participants practiced self-ear-cleaning and majority of those who did, believed that it was for ear hygiene.

According to, Afolabi, Kodiya, Bakari and Ahmad (2009), the tradition of self-ear cleaning should be discouraged as it may be an otologic poison with unfavourable long-term effects such as otitis externa, otomycosis and impaired hearing. The practice is also associated with some other diseases of the ear (Afolabi, Kodiya, Bakari, \& Ahmad, 2009).

\section{Methods}

In this review paper, we aimed at determining the prevalence of self-ear cleaning, the methods used to perform the practice and the associated complications. We reviewed seven articles with similar objectives; self-ear cleaning practices and the associated risk of ear injuries. Electronic retrieval of articles for review was done from PubMed, Google and Google scholar with key-ward - self-ear cleaning, ear-wax, cerumen cotton but use. Many articles were retrieved but only seven were about self-ear cleaning and could be included in this review. The inclusion criteria included: article published in English language; study carried out between 2005 and 2020 inclusive; article discussing self-ear cleaning, materials used and complications associated. Articles older than 15 years or published in languages other than English were excluded.

\section{Results}

The results of our search, screening and evaluation of the studies are summarized in the table below: 
Table 1

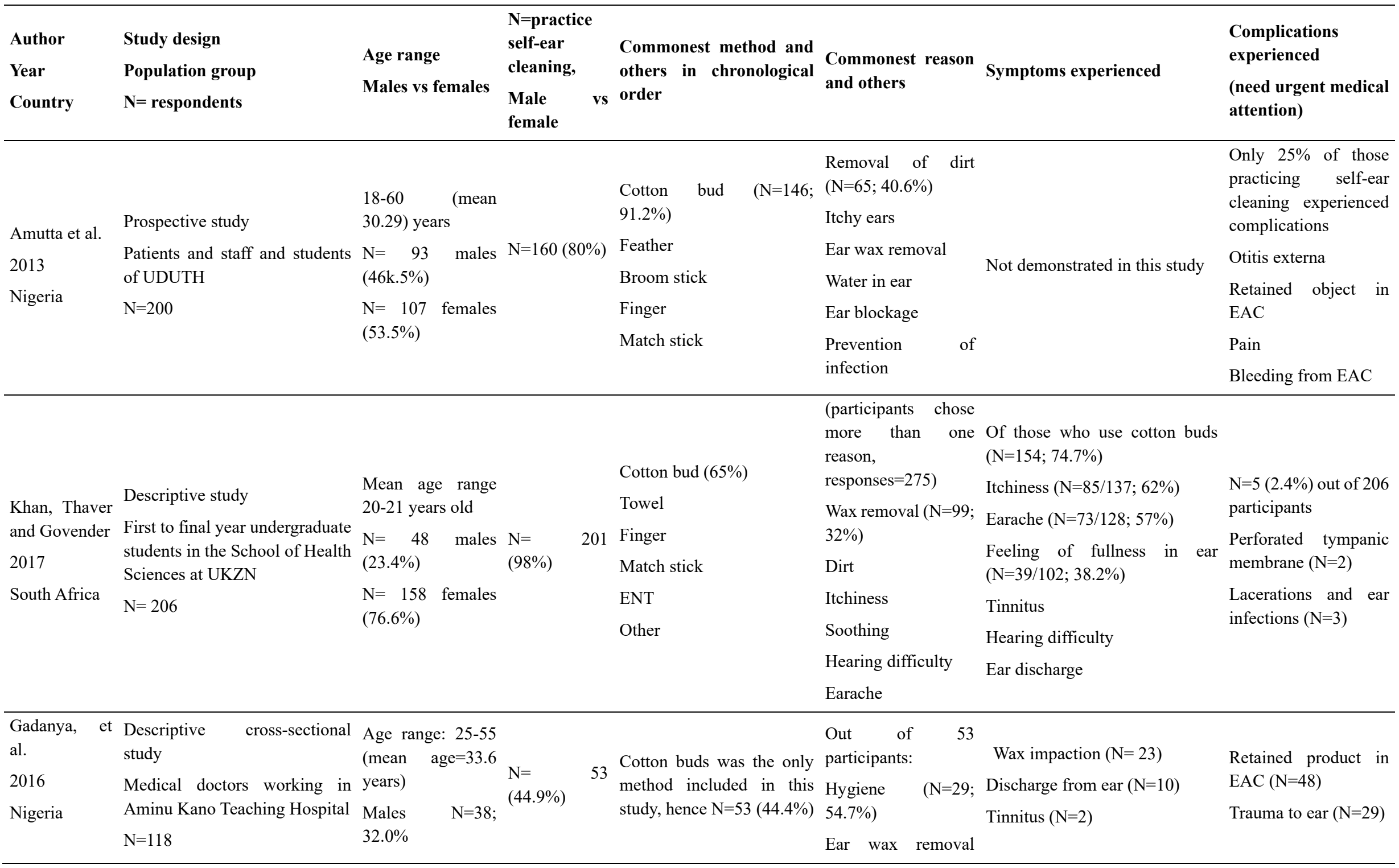




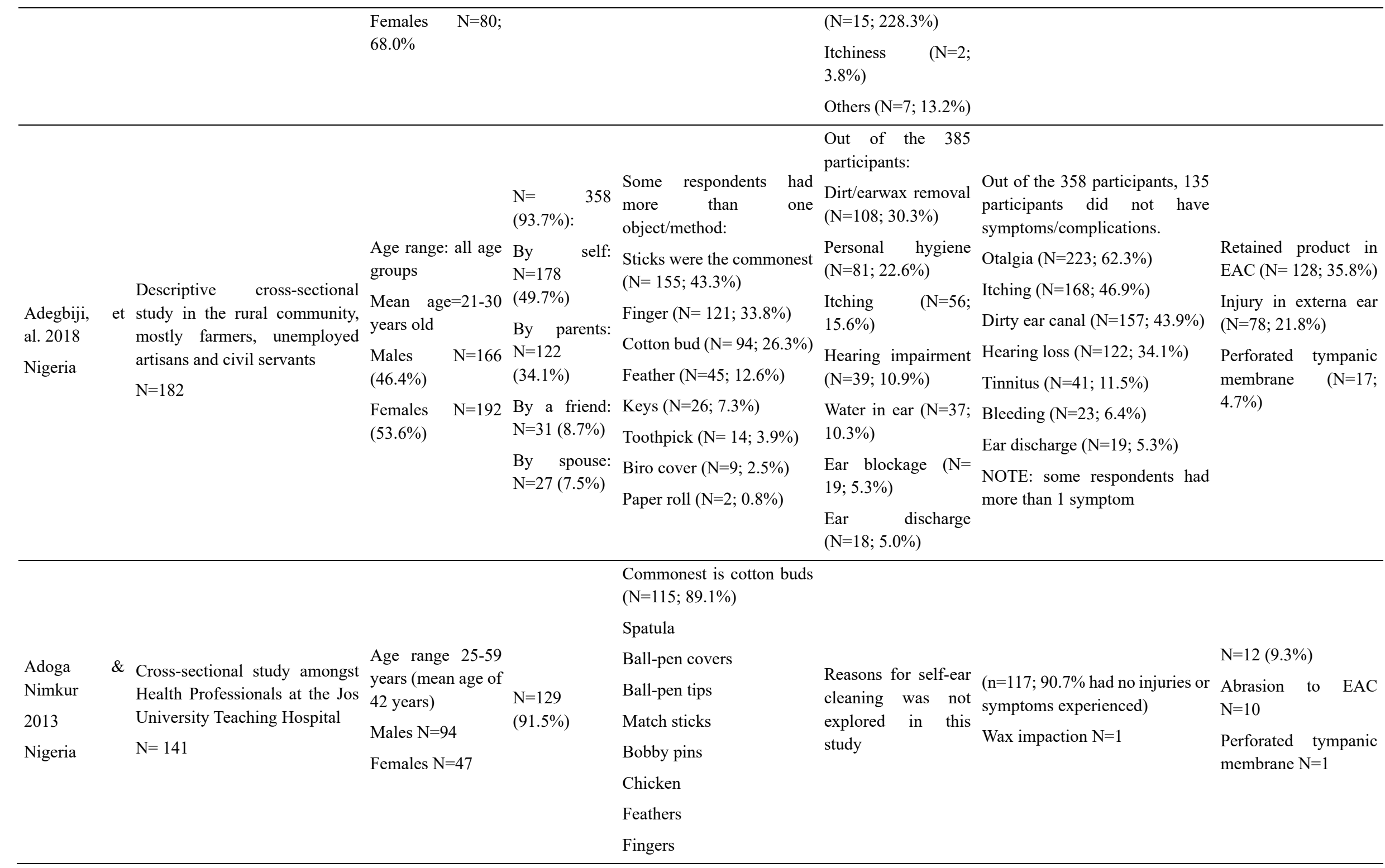




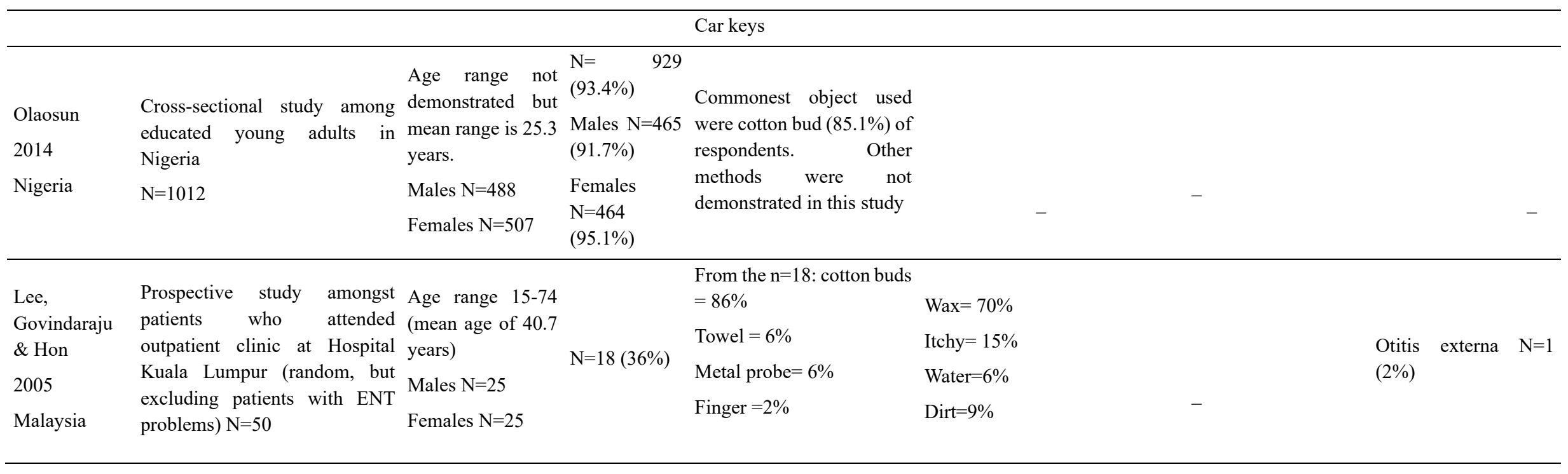


In a prospective study done in Nigeria, amongst patients and healthy individuals (staff and students) from Usmanu Danfodiyo University Teaching Hospital (UDUT), $19.5 \%(\mathrm{n}=39)$ did not engage in self-ear cleaning practice while $80 \%(\mathrm{n}=160)$ practiced self-ear cleaning (Amutta et al., 2013). The participants were in the age range of 18-60 years with mean age of 30.29 years old. There were more females than males, $n=107(53.5 \%)$ and $n=93(46.5 \%)$ respectively. In descending order, the methods or objects used for self-ear cleaning were cotton buds $(\mathrm{n}=146$; $91.2 \%)$, biro cover/tip $(n=6 ; 3.7 \%)$, feather $(n=3 ; 1.9 \%)$, broom stick $(n=2 ; 1.3 \%)$, finger $(n=2 ; 1.3 \%)$ and match stick $(\mathrm{n}=1 ; 0.6 \%)$. The reasons for performing self-ear cleaning were removal of dirt with $\mathrm{n}=65(40.6 \%)$, itchy ears $(n=48 ; 30 \%)$, ear wax $(n=25 ; 15.6 \%)$, ear blockage $(n=22 ; 13.8 \%)$, and water in the ear $(n=10,6.2 \%)$. Out of the160 respondents who admitted to self-ear cleaning practices, $25 \%(\mathrm{n}=40)$ of them experienced complications. The complications included otitis externa $10.6 \%(n=17)$, retained object in external auditory canal (EAC) $6.9 \%$ $(\mathrm{n}=11)$, pain $6.3 \%(\mathrm{n}=10)$ and bleeding from $\mathrm{EAC} 1.2 \%(\mathrm{n}=2)$.

In another descriptive study in South Africa amongst undergraduate students in the School of Health Sciences at the University of KwaZulu-Natal (UKZN) (Khan et al., 2017), there were a total participant of $n=206$ with a mean age range of 20-21 years old. Majority of these participants were females $n=158(76.6 \%)$, compared to males $n=48$ (23.4\%). Out of 206 participants, $98 \%(\mathrm{n}=201)$ reported to have practiced self-ear cleaning. The methods used for self-ear cleaning in this study included cotton buds (65\%), towel (20\%), fingers (5\%), match sticks (2\%), ENT (2\%) and others (3\%). The most common reason for self-ear cleaning included removal of wax $36 \%(\mathrm{n}=99)$, dirt $31 \%$ $(n=85)$, ear itchiness $20 \%$, soothing $8 \%$, hearing difficulty $3 \%$ and earache $2 \%$. Only $2.4 \%(n=5)$ of the 206 respondents experienced complications that required medical attention, 2 with perforated tympanic membrane of which one needed tympanoplasty and 3 had lacerations and ear infection.

In a descriptive cross-sectional study amongst a group of medical doctors at Aminu Kano Hospital in Nigeria by Gadanya, Abubakar, Ahmed, and Maje (2016), out of a total of 118 participants, $44.9 \%(n=53)$ admitted to having done self-ear cleaning before. All of them used cotton buds. The reasons given for self-ear cleaning included keeping good hygiene $54.7 \%(\mathrm{n}=29)$, removal of ear wax $28.3 \%(\mathrm{n}=15)$, itchiness $3.8 \%(\mathrm{n}=2)$ and other reasons $13.2 \%(\mathrm{n}=7)$. In this group, complications from the practice that required urgent medical attention included retained foreign body $(n=48)$ and trauma to the ear $(n=29)$.

In a descriptive cross-sectional study in a rural community of Nigeria by Adegbiji, Olajide, Olubi \& Aluko (2018), the participants were mainly farmers and civil servants. The total number of respondents was 382 of whom 166 (46.4\%) were males and 192 (53.6\%) were females. The mean age group was 21-30 years of age. Only 47.9\% $(\mathrm{n}=178)$ had practiced self-ear cleaning. The objects used to clean ears included sticks $43.3 \%(\mathrm{n}=155)$ followed by fingers $33.8 \%(\mathrm{n}=121)$, cotton buds $26.3 \%(\mathrm{n}=94)$, feathers $12.6 \%(\mathrm{n}=45)$, keys $7.3 \%(\mathrm{n}=26)$, toothpick $3.9 \%$ $(\mathrm{n}=14)$, biro cover $2.5 \%(\mathrm{n}=9)$ and paper roll $0.8 \%(\mathrm{n}=2)$. The reasons for self-ear cleaning in this group included dirt/earwax removal $30.3 \%(n=108)$, personal hygiene $22.6 \%(n=81)$, itching $15.6 \%(n=56)$, hearing impairment $10.9 \%(n=39)$, water in ear $10.3 \%(n=37)$, ear blockage $5.3 \%(n=19)$ and ear discharge $5.0 \%(n=18)$. Complications experienced by this group included retained foreign bodies in EAC 35.8\% $(\mathrm{n}=128)$ of which $21.8 \%$ $(\mathrm{n}=78)$ received medical attention to remove foreign bodies, injury to external ear $21.8 \%(\mathrm{n}=78)$ and perforated tympanic membrane $4.7 \%(\mathrm{n}=17)$.

A cross-sectional study involving 141 (94 males and 47 females) Health professionals at Jos University Teaching Hospital in Nigeria by Adoga and Nimkur (2013), demonstrated that $91.5 \%(\mathrm{n}=129)$ of the participants practiced self-ear cleaning. The participants were in the age range $25-59$ years with mean age of 42 years. $89.1 \%(n=115)$ of those who practiced self-ear cleaning used cotton buds. Other methods/materials used included spatula, ball-pen covers, ball-pen tips, matchsticks, bobby pins, chicken feathers, fingers and car keys. This study did not explore the reasons for self-ear cleaning. Only $9.3 \%$ of those who practice self-ear leaning reported complications including abrasion to EAC, perforated tympanic membrane and wax impaction.

In a cross-sectional study involving 1012 young educated participants (488 male and 508 females) in Nigeria by Olaosun (2014), found that 929 (93.4\%) of all participants (465 males and 464 females) practiced self-ear cleaning. In this study the commonest object, $85.1 \%$, used were cotton buds. This study also did not explore the reasons for self-ear cleaning.

A prospective study involving 50 outpatients (25 males and 25 females) in Kuala Lampur, Malaysia by Lee, Govindaraju and Hon (2005) demonstrated $36 \%(n=18)$ practiced self-ear cleaning practices. Their age range was 15-74 years with a mean range of 40.7 years. Of those who practiced self-ear cleaning, $85 \%$ used cotton buds. Other objects used included towel $(6 \%)$, metal probe $(6 \%)$ and finger $(2 \%)$. The reasons for self-ear cleaning identified in this study were wax $(70 \%)$, itchiness $(15 \%)$, water in ear $(6 \%)$, and dirt in ear $(9 \%)$. Only one respondent reported a complication of otitis externa as a result of self-ear cleaning. 
In a prospective study carried out at the Tundun-wada community and National Ear Care Centre, Kaduna by Abdulrahmnam and colleagues, about $27 \%$ had ear discharge, $22 \%$ wax impaction and $12 \%$ had foreign bodies as complications resulting from self-ear cleaning. In this study there was a total of 372 participants with age range 1-76 years, a mean age of 30.37 years, median age 29.00 (S.D. $=13.79$ ) and M:F ratio of 1:1. Mothers responded for their children except for grown up. About $47.3 \%$ of the subjects were unemployed and these were either children or complete house wife. About $90 \%$ of the subjects interviewed practiced self-ear cleaning and over $90 \%$ believed the ear should be cleaned to remove wax, over $50 \%$ because of itchiness or for cosmetic reasons. Cotton bud was the commonest material used for cleaning.

\section{Discussion}

\subsection{Prevalence of self-ear cleaning}

The findings in the articles reviewed showed the prevalence of self-ear cleaning to be persistently above $90 \%$. Only two studies (Lee, Govindaraju \& Hon, 2005 and Gadanya et al., 2016) had lower prevalence of 36\% and 44.9\% respectively. It is, therefore, evident that the self-ear cleaning is a common practice. Since these studies were conducted in different settings (educated population, health professionals, university students, rural settings), it can be deduced that the practice of self-ear cleaning is common in all social backgrounds. The prevalence is mainly high in those in their $2^{\text {nd }}-3^{\text {rd }}$ decades (Amutta et al., 2013; Khan, Thaver, \& Govender, 2017; Gadanya et al., 2016; Adegbiji et al., 2018; Olaosun, 2014). Only two studies (Lee, Govindaraju, \& Hon, 2005; Adoga \& Nimkur, 2013) had peaks in the prevalence in the practice in the $4^{\text {th }}$ decade. Regarding gender, only one study by Olaosun (2014) analysed gender difference and found that females are more likely to perform self-ear-cleaning than males. According to Adegbiji et al. (2018), however, females are generally more active in personal hygiene compared to males.

\subsection{Materials used for Self-Ear Cleaning}

Several methods/materials were found to have been used for self-ear cleaning in these studies, but what came most commonly were cotton buds. Significantly, however, a study by Adegbiji et al. (2018) carried out in the rural community showed that sticks were more commonly used (43.3\%), followed by fingers (33.8\%) and cotton buds (26.3\%). It, therefore, can be deduced that the object used is dependent on the environment and the socio-economic status of the population. Hence, sticks, feathers and fingers are more commonly used in rural areas whereas cotton buds are commonly used in urban settings (Adegjibi et al., 2018).

\subsection{Reasons for Self-Ear Cleaning}

In the articles that were reviewed, there were several reasons for individuals to practice self-ear cleaning. The commonest reason was to remove dirt/wax from the ear. Wax is wrongly perceived as dirt or debris and thus the urge to remove it. The other reasons were itchiness, feeling of water in the ear, soothing, and ear blockage or impaired hearing. It is evident in several studies that earwax is believed to be dirt and unhygienic due to its brown sticky characteristic. However, Cerumen (earwax) is a normal physiologic excretion from the ceruminous and the sebaceous glands forming part of the outer third of external auditory canal. Earwax is composed of glycopeptides, lipids, hyaluronic acid, sialic acid, lysosomal enzymes and immunoglobulins. Earwax serves a protective function, by maintaining an acidic environment ( $\mathrm{pH}$ of $5.2-7.0)$ in the external auditory canal as well as lubricating the canal. Additionally, earwax has antibacterial and antifungal properties (Oladeji, Babatunde, Babatunde, \& Sogebi, 2015). According to Khan et al., (2017), self-ear cleaning practices has evidently been found to compromise the integrity of the ear's self-cleansing mechanism.

\subsection{Complications of Self-Ear Cleaning}

Some subjects from all articles reviewed have had complications resulting from self-ear cleaning. According to Khan et al. (2017), the most frequently seen complications in the ENT departments are retained cotton bud ends as well as match stick ends stuck in the ear. Other complications of self-ear cleaning include perforated tympanic membrane and otitis externa. Majority of patients who get complications are from the rural setting (Adegbiji et al., 2018). Nonetheless, most of these complications are self-limiting. In a study by Khan et al. (2017), however, 5 of 206 participants had serious complications two of whom experienced perforated tympanic membrane and one required tympanoplasty.

\section{Recommendations}

Based on the literature, there is no doubt that self-ear cleaning is a common practice. It is also evident that risks such as injuries to the inner ear and complications such as perforation of tympanic membrane and retention of foreign bodies are real. We therefore recommend the following: 
- Health education against self-ear cleaning. It is recommended that priority be put on teaching primary school pupils to avoid putting objects in their ears. They should as well be made aware of the possible dangers/complications of doing so right from the young age such that the vice should not be done in adulthood.

- For adults and the general public, health education against self-ear cleaning could form part of health promotion package given at primary health care facilities. The community should be sensitized about the danger and the complications that may occur because of self-ear cleaning practices. Ear, nose and throat (ENT) department should create awareness campaign conveying basic information on the danger of self-ear cleaning practices; people should be encouraged to develop a health seeking behaviour from trained health personnel.

- Health professionals need to promote safe practices for the public to follow. The review has shown that some health professionals also practice self-ear cleaning yet they know that it is harmful. This habit should be discouraged, as it is a slow otologic poison leading to potential risks of ear injuries (Afolabi et al., 2009).

\section{Conclusion}

The practice of self-ear cleaning among all ages is common. In addition to ridding the ear of its natural protection, self-ear cleaning is associated with a risk of injury to the ear drum, retention of foreign bodies and other complications as someone blindly inserts objects into the ear canal. Community education to avoid this practice is therefore of paramount importance. Trained health care providers should be consulted whenever someone has a problem related to hearing or any other symptom.

\section{Competing Interests Statement}

The authors declare that there are no competing or potential conflicts of interest.

\section{References}

Abdullahi, M., Aliyu, D., Amutta, S., Egili, E., Iseh, K. R., Obembe, A., \& Yunusa, M. A. (2013). Sociodemographic Characteristics and Prevalence of Self Ear Cleaning in Sokoto Metropolis. International Journal of Otolaryngology and Head \& Neck Surgery, 2(6), 276-279. https://doi.org/10.4236/ijohns.2013.26057

Abubakar, S., Ahmed, A., Gadanya, M., \& Maje, A. Z. (2016). Prevalence and Attitude of Self-ear Cleaning with Cotton Bud among Doctors at Aminu Kano Teaching Hospital, Northwestern Nigeria. Nigerian Journal of Surgical Research, 17(2), 43-7. https://doi.org/10.4103/1595-1103.194215

Adegbiji, W. A., Aluko, A. A. A., Olajide, G. T., \& Olubu, O. (2018). A Study Profile of Self Ear Cleaning in Nigerian Rural Community. Int J Recent Sci Res., 9(7), 28181-28185. http://dx.doi.org/10.24327/ijrsr.2018.0907.2412

Adoga, A. A., \& Nimkur, T. L. (2013). Ear care: Knowledge, Attitude and Practice amongst Health Professionals at the Jos University Teaching Hospital. East African Journal of Public Health, 10(1), 274-281.

Afolabi, A. O., Ahmad, B. M., Bakari, A., \& Kodiya, A. M. (2009). Attitude of self-ear cleaning in black Africans: any benefit? PubMed, East Afr $J$ Public Health, 6(1), 43-6. PMID: 20000063. https://doi.org/10.4314/eajph.v6i1.45743

Babatunde, L., Babatunde, O., Oladeji, S., \& Sogebi, O. (2015). Knowledge of Cerumen and Effect of Ear Self-Cleaning Among Health Workers in a Tertiary Hospital. Journal of the West African College of Surgeons, $5(2), 117-133$.

Govender, S. M., Khan, N. B., \& Thaver, S. (2017). Self-ear cleaning practices and the associated risk of ear injuries and ear-related symptoms in a group of university students. Journal of Public Health in Africa, 8(2), 555. https://doi.org/10.4081/jphia.2017.555

Govindaraju, R., Hon, S. K., \& Lee, L. M. (2005). Cotton Bud and Ear Cleaning- A Loose Tip Cotton Bud? Med J Malaysia, 60(1), 85-88.

Olaosun, A. O. (2014). Self-Ear-Cleaning Among Educated Young Adults in Nigeria. Journal of Family Medicine and Primary Care, 3(1), 17-21. https://doi.org/10.4103/2249-4863.130262 


\section{Copyrights}

Copyright for this article is retained by the author(s), with first publication rights granted to the journal.

This is an open-access article distributed under the terms and conditions of the Creative Commons Attribution license (http://creativecommons.org/licenses/by/4.0/). 